\title{
FAMINE, AFFLUENCE, AND AMORALITY
}

\author{
David Sackris ${ }^{1}$ \\ ${ }^{1}$ Arapahoe Community College \\ Original scientific article - Received: 14/07/2021 Accepted: 18/09/2021
}

\begin{abstract}
I argue that the debate concerning the nature of first-person moral judgment, namely, whether such moral judgments are inherently motivating (internalism) or whether moral judgments can be made in the absence of motivation (externalism), may be founded on a faulty assumption: that moral judgments form a distinct kind that must have some shared, essential features in regards to motivation to act. I argue that there is little reason to suppose that first-person moral judgments form a homogenous class in this respect by considering an ordinary case: student readers of Peter Singer's "Famine, Affluence, and Morality". Neither internalists nor externalists can provide a satisfying account as to why our students fail to act in this particular case, but are motivated to act by their moral judgments in most cases. I argue that the inability to provide a satisfying account is rooted in this shared assumption about the nature of moral judgments. Once we consider rejecting the notion that first-person moral decisionmaking forms a distinct kind in the way it is typically assumed, the internalist/externalist debate may be rendered moot.
\end{abstract}

Keywords: Meta-ethics; moral judgment; internalism; externalism; natural kinds 


\section{Introduction}

Most academic philosophers have taught a class on Peter Singer's 1972 article 'Famine, Affluence, and Morality' at least once. In his essay, Singer critically assess the lifestyle of modern Westerners, illustrating how easily we could save the lives of the desperately poor if we would only choose to forgo trivial enjoyments, for example, exchanging our daily $\$ 5$ latte for a $25 \notin$ cup of Folger's, while donating the remainder to charity. Surely the life of a human being is more important than the momentary pleasure of a latte. Therefore, Singer posits, one is morally required to donate that remaining $\$ 4.75$ to famine relief and make do with the less enjoyable good.

Singer's central argument is exceedingly simple and, prima facie, difficult to rebut (especially for introductory level students). ${ }^{1}$ Typically, a substantial group of students will say that they think Singer is right, concluding that Westerners should do more to alleviate global suffering. But here is the rub: very few students seem to actually change their lifestyle one iota as a result of Singer's argument. ${ }^{2}$

Especially illustrative of this phenomenon is the class discussion of the central thought experiment in Singer's article. It goes like this: suppose you are walking down the street and see a small child drowning in a shallow pond. Surely you would feel morally obligated to save the child, even if it meant ruining the pants you were wearing. The value of the pants pales in comparison to the life of a human being who needs help through no fault of their own $(1972,231)$. The overwhelming majority of the students tend to agree with Singer that it would be morally wrong not to help the child, and a significant number even suggest that they would be willing to jail any person who ignores the drowning child and walks by. However, when the conversation moves to the starving children of East Bengal, students typically become less sure about the wrongness of not helping. Roughly, most students think that it would be good to help such children, and that people ought to do so, yet students rarely express the opinion that not helping is a significant moral wrong or that non-helpers belong in jail. They fail to express this opinion even though these same students are typically unable to poke significant holes in Singer's reasoning that the starving children of East Bengal are not relevantly different from a child drowning right in front of them. After lengthy discussion, some students reject Singer's ultimate conclusion that they are morally obligated

\footnotetext{
${ }^{1}$ And perhaps it can't be rebutted because it's a sound argument. It is not my aim to discuss the merits of Singer's argument here, but instead use it as an illustrative example.

${ }^{2}$ Admittedly, a small number of students are convinced by Singer's argument and do act on their newfound judgment; the exceptions are so notable that Nicholas Kristoff (2015) wrote a column about it.
} 
to help the children of East Bengal without any real reason; many more appear to accept his conclusion but do nothing to conform their behavior to their newly formed judgment. ${ }^{3}$

This phenomenon of being intellectually convinced by a moral philosophical argument, yet seemingly unmotivated to behave according to one's conviction, appears to count as another piece of evidence in the long-standing philosophical dispute over the nature of moral judgment and motivation known as the externalist vs. internalist debate. Externalists hold that there is a basic disconnect between beliefs and behavioral motivation. Moral judgments, externalists claim, are not in themselves motivating. And we might agree that when discussing Singer's article, our students' beliefs and behaviors (or lack thereof) lend strong empirical support for such a position. The problem with simply accepting externalism, however, is that it is also clearly true that many moral judgments are, as a matter of fact, motivating: people typically act on their considered moral judgments. ${ }^{4}$ In fact, this is precisely what internalists have traditionally maintained: one cannot make a real moral judgment without being motivated to act. ${ }^{5}$ In this respect, internalism serves as a kind of 'best explanation' of typical human behavior.

Most likely our students would act on their moral judgment that they ought to save the drowning child right in front of them; I also can't deny that most students fail to act, and do not appear to be strongly motivated to act, on their in-class judgments about famine relief. The question then is this: how do we make sense of such mixed evidence, not from a normative standpoint but from a descriptive one ${ }^{6}$ That is, how do we account for the clearly observable phenomena of ordinary moral judgments whereby some moral judgments are highly motivating, almost always resulting in action, and other moral judgments do not result in any action or even any apparent motivation to act?

I argue that if we aim to account for real-world ethical decision-making by ordinary people, we should reconsider the internalist/externalist debate and entertain the possibility that neither view, by itself, is able to offer the correct account. Through an explicit consideration of this curious case, I aim to raise the following, neglected possibility: What if moral judgments do not form a distinct kind, at least in respect to motivational impact? I

\footnotetext{
${ }^{3}$ King $(2018,635)$ also makes the latter observation about her students and their reading of 'Famine, Affluence, and Morality'.

${ }^{4}$ Barring some other, overriding obligation.

${ }^{5}$ Both externalism and internalism will be carefully considered and defined in subsequent sections.

${ }^{6}$ It seems that theories of moral judgment are often about how moral judgments ought to or should be made (i.e., they are prescriptive), but the point here is that we should focus more on the observable behavior of ordinary decision-makers.
} 
ultimately conclude that we have good reason to reconsider the view that all moral judgments will be either necessarily motivating or motivationally inert. That is, there may be different kinds of judgments that we classify as 'moral' yet, despite this ordinary language classification, it is not the case that these judgments will have all the same significant properties.

I begin by considering what the internalist and externalist might say about our student readers of 'Famine, Affluence, and Morality' and why their likely analyses of the situation are unsatisfactory. I then turn to what appears to be a shared, unargued for assumption of both internalists and externalists: that moral judgments form a distinctive kind and have necessary, shared features. I then argue that such an assumption should be reconsidered at least in respect to motivational features. ${ }^{7}$ Reconsidering this assumption could lead to a resolution of the externalist/internalist debate.

\section{What the internalist has to say about our students' judgments and behaviors}

Let's suppose, for a moment, that moral judgments are necessarily motivating (i.e., that some version of internalism is true) ${ }^{8}$ Obviously, the majority of students are not acting on their considered moral judgments in this case. Further, they do not appear to be highly motivated to act on said judgments; there are almost no barriers to their acting - they could donate through their smart phones immediately after class - yet they still typically fail to act. ${ }^{9}$ One of the central difficulties with this debate is that it is nearly impossible to determine whether someone is at least minimally motivated by their judgment even when they fail to act on it. Given these facts, what must the internalist say about our students? We have three options:

a) Most students are practically irrational.

b) Most students are not making "real" moral judgments.

c) Most students experience some minimal motivation that does not arise to the level of action. ${ }^{10}$

\footnotetext{
${ }^{7}$ Few contemporary authors have questioned this assumption that moral judgments form a distinct kind. Sinnott-Armstrong and Thalia (2012, 2014), and Stich (2006) constitute exceptions.

${ }^{8}$ Internalism is both interpreted as a conceptual truth and as an empirical one. For example, Smith (1994) is essentially defending a defeasible conceptual connection, and Brink (1986) argues that if an amoralist is merely conceptually possible, then internalism is defeated. Prinz (2007) and Björnnson (2002) offer empirical arguments for internalism. An exact definition of internalism is difficult to pin down; for an overview, see Smith (1994, chapter 3) and Korsgaard (1986).

${ }^{9}$ Almost is the key word here. I assume that most American college students can spare a few dollars for famine relief at least once in a while.

${ }^{10}$ King $(2018,636)$ also lists these as the three likely responses for the internalist.
} 
We begin with (a). For the students to be considered practically irrational, it must be the case that they are not at all motivated by their moral judgment. The rational internalist (henceforth, rationalism), for example, maintains that the recognition of a moral requirement provides a reason for action, and that such reasons motivate. Acting, or being motivated to act, on the recognition of such normative reasons is a requirement of rationality, and so rational individuals will be motivated to act on their moral judgments, barring instances of practical irrationality (Smith 1994). On a position like Smith's, barring the possibility that the students have some other, overriding moral obligation that conflicts with contributing to famine relief, we are led to conclude that the vast majority of our students are practically irrational. Let's see why.

Here is how Smith describes his internalist position:

If an agent believes that she has a normative reason to $\varphi$, then she should rationally desire to $\varphi$. (Smith 1994, 148)

Smith accepts that there is a defeasible connection between our judgments and actions; namely, we don't always act on our moral judgments. This requires an explanation. He states:

If an agent judges that it is [morally] right for her to $\varphi$ in circumstances $\mathrm{C}$, then either she is motivated to $\varphi$ in $\mathrm{C}$ or she is practically irrational. (Smith 1994, 61).

By 'practically irrational' Smith means individuals who 'judge it right to act in various ways' but fail to act on those judgments (Smith 1994, 61). Such individuals must be suffering from 'weakness of will and other similar forms of practical unreason on their motivations' (Smith 1994, 61). If an individual is not motivated by what she considers a reason for action, then 'she fails to be rational by her own lights' (Smith 1994, 62). So, if a student judges that Singer has made a convincing argument, yet fails to be motivated to act on this judgment, then they are practically irrational.

To write off the majority of our students as practically irrational seems a bit too quick: we shouldn't rush to embrace a norm of rationality that does not fit the majority of seemingly rational individuals' reasoning and subsequent behavior. ${ }^{11}$ Prima facie, my experience teaching ethics seems like an objection to Smith's argument: here are seemingly rational individuals who understand Singer's reasons (and have good reason to try

\footnotetext{
${ }^{11}$ Williams thinks it is too quick as well, his point being that by the students' own lights they are acting rationally $(1979,25)$. Smith (1994) aims to refute this claim. See especially chapter 5.
} 
and understand his reasons, given that they will be tested on the material), accept them, yet seemingly fail to be motivated to act. But these same individuals are motivated to act on their moral judgments in many other routine situations, e.g., tracking down a fellow student who left their textbook in the classroom. Performing such an act may require more work than donating to charity, which can be accomplished via one's smartphone. ${ }^{12}$

Part of the problem with Smith's position, and many accounts of normative judgment like his, is that it is sometimes unclear what the project is supposed to be: a descriptive one or a prescriptive one. ${ }^{13}$ Sadler (2003) astutely points this out. Is Smith's theory an analysis of the concept 'moral judgment' as used by an ideal agent, i.e., is it a theory about the nature of judgments as made by good and strong-willed persons, or is it meant to be an analysis of the concept as employed by ordinary individuals? It seems clear that he aims to do the latter. ${ }^{14}$ Yet his account fails to explain what is going on in the typical ethics course, unless he wants to call the majority of undergraduates, and, I would contend, the majority of human beings, practically irrational. There would be no internalist/externalist debate if it didn't seem possible, in a very ordinary kind of way, to make a moral judgment without necessarily feeling motivated to act on said judgment. So, it is hard to see how failing to be motivated deserves the charge of practical irrationality. ${ }^{15}$

So, on a rationalist account like Smith's, in order to explain why most students fail to be strongly motivated to act on their judgment that more should be done for the starving children of East Bengal, we have to either accept that the majority of people are practically irrational even in contexts of careful deliberation, like a philosophy classroom, or accept that (a) does not appear to offer a satisfying analysis of our student's failure to act. The latter seems like the more plausible conclusion.

Let's now consider (b): our students are not making 'real' moral judgments. Instead of maintaining that our students are practically irrational or suffer from a contagious case of weakness of will, the

\footnotetext{
${ }^{12}$ Even if the reader is unsure of what to make of our student readers' judgments and for that reason dislikes my focus on this example, the phenomena of intellectually judging an act to be morally obligatory yet failing to actually carry it out does not seem to be all that unusual. The judgments we make concerning what we ought to do while lying awake at night are often not the ones we follow through on in the morning.

${ }^{13}$ Similarly, it is unclear whether Carroll's (2015) theory of aesthetic experience is meant to be a descriptive or prescriptive one. See Sackris and Larsen (2020).

${ }^{14}$ See especially Smith (1994, chapters 1 and 2).

${ }^{15}$ Setiya (2004) points out that even it if it is true that the concept 'moral judgment' necessarily includes motivation, if coming to see this requires significant philosophical reflection, then it is hardly fair to call those who fail to realize this 'irrational'.
} 
internalist could maintain that the students are not making 'real' moral judgments. If motivation is part of the concept 'moral judgment', then lack of motivation might indicate that the concept is not actually being deployed. Rosati (2016) emphasizes the connection between failure to act and insincerity: '[I]f an individual makes a moral judgment, she is, ceteris paribus, motivated; if she is not motivated, she was not making a sincere and competent moral judgment at all, appearances to the contrary notwithstanding'. ${ }^{16}$ So, if the students aren't motivated to act, then we might conclude that they are merely saying what they think we, their professors, want to hear, or that they have some other reason for falsely reporting their agreement with Singer.

There are additional considerations. It may be true that they have limited ability to act in class at the moment of the discussion of famine relief, so in that sense the critical reader may think this is a poor example. However, I ask students if they plan to go out and do anything differently (planning to act differently would seem to indicate current motivation), and the next class bring up the same sorts of questions: has anyone forgone their daily Starbuck's latte in favor of famine relief? Has anyone, instead of paying their fraternity dues, considered donating those dues to famine relief? Perhaps the chorus of 'Nos' supports the contention that they haven't made real moral judgments.

Yet it is not clear why we should think that our students are not making 'real' moral judgments in this particular case, when we would be unlikely to say the same thing about other topics where it would be difficult for students to act in any fashion even if they wished to, e.g., we might ask our students whether they think the use of torture by the state is permissible. Here the internalist would likely complain that there is a significant difference between this case and my preferred example: unlike the issue of famine relief, it is virtually impossible for students to act on their judgments about state-sanctioned torture in or out of class; ${ }^{17}$ nonetheless, they could still be motivated by such judgments. Their motivation is merely frustrated in the torture case. The problem is that we don't have any direct evidence that they are motivated and frustrated; such direct evidence is unavailable. To say that they must be motivated and that their motivations are merely frustrated when considering torture sounds a bit like assuming the very thing that is supposed to be proven - whether they are actually motivated by their in-class moral judgments.

\footnotetext{
${ }^{16}$ Harman offers a similar formulation $(1977,33)$, as does Blackburn $(1984,188)$.

${ }^{17}$ For the most part. Of course, they could organize protests, run for office, etc., but there is no single action they could easily take to bring about their judgment regarding state sanctioned torture.
} 
Given this problem of opacity, most philosophers likely just assume, whether they are committed internalists or externalists, that students are making real moral judgments in our ethics classes, whatever the topicwhether or not they have the ability to act on their judgments. If we do not believe that our students are capable of genuine moral reflection and judgment in our classes, we should probably stop teaching ethics. So (b) probably isn't the right answer.

That leaves us with (c). Let's now consider whether the internalist should be attracted to a position on which all moral judgments are accompanied by some minimal motivation, but that motivation need not rise to a level at which the individual would be motivated enough to act, even in situations where there are no practical obstacles to acting. On this position, although the students who agree with Singer don't do anything, they are nonetheless minimally motivated by their judgments.

First, let's consider whether a rationalist should be attracted to such a position. To review, on Smith's position, if students have judged that Singer is right, then they should thereby be motivated to act. Smith has little to say about degrees of motivation: however, he routinely appeals to depression as an example of a practical irrationality that completely extinguishes one's motivation to act:

It is a commonplace, a fact of ordinary moral experience, that practical irrationalities of various kinds-various sorts of 'depression' as [Michael] Stocker calls them [1979, 744]—can leave someone's evaluative outlook intact while removing their motivation altogether. (Smith 1994, 120-121) ${ }^{18}$

Appealing to a completely will-draining depression fails to get at the core suggestion in (c): that our students have some minimal motivation that accompanies their judgment, but that the motivation is simply not strong enough to get them to act. In the context of teaching 'Famine, Affluence, and Morality', it is unlikely that most of our students are suffering from a kind of global, will-draining form of depression; if that were the case, they likely wouldn't have even made it to class.

If one wants to make sense of a claim like (c), identifying moral motivation with emotion may seem to be a natural move. If one advocates for a sentimentalist theory of morality and holds, like Jesse Prinz (2007), that

\footnotetext{
${ }^{18}$ For additional examples of Smith focusing on completely debilitating forms of mental illness, see pages 123 and 125 of his (1994).
} 
moral judgments are constituted by emotions, then one has good reason for being attracted to (c).${ }^{19}$ As Prinz states:

If moral judgments contain moral concepts, and moral judgments have an emotional composition, then moral judgments motivate action, because emotions are motivational states. [Sentimentalism] entails internalism (...). (Prinz 2007, 102)

On this view, every moral judgment does in fact contain some minimal motivation, and our students are likely feeling some emotions as they read of the plight of individuals caught up in tragic circumstances. On this position, even in cases where students fail to act on their judgments, we still cannot conclude that they weren't motivated at all: given the sentimentalist definition of a moral judgment, we should assume they feel some minimal motivation. Furthermore, it would be exceedingly difficult to prove that there isn't some kind of minimal motivation that corresponds to their judgment. Therefore, internalism, on this interpretation, is true by default.

Yet such a position is also problematic: lacking direct access to the subjective states of moral decision makers, it is impossible to show that moral judgment is, or is not, always accompanied by minimal motivation when the only readily available evidence is whether the individual ultimately acts. Elinor Mason dubs a view along the lines of (c) 'Weakest Internalism'. She says

The only difference between weakest internalism and externalism is that weakest internalism says that when there is a moral judgement there is always some level of motivation, however slight and ineffective.... The chief point of weakest internalism seems to be to satisfy the basic internalist intuition that it is odd to judge that you ought to do something and yet not be motivated at all. But without an independent argument for internalism, that intuition is not a good enough justification for adding the internalist clause to the theory. (Mason 2008, 144)

What Mason means by 'an independent argument for internalism', I suppose, is something like this: an empirical argument in favor of the internalist thesis. So, if, e.g., sentimentalism is true and moral judgments

\footnotetext{
${ }^{19}$ Additional modern advocates of sentimentalism include Nichols (2004), Gill and Nichols (2008), and Slote (2010).
} 
are in fact composed (in some fashion) of emotional states, we would then need empirical evidence that moral emotions, or all emotions, contain some minimal amount of motivation. Do we have any such evidence along these lines?

We would need an argument that shows either of the following: 1) that there is only some small subset of emotions involved in moral judgments, all of those emotions are in fact motivating, and that there is no other basis for moral judgments; or 2) that all emotions are motivating and that that there is no other basis for moral judgment. It would be very difficult to empirically demonstrate the former, ${ }^{20}$ and Prinz, one of the chief contemporary supporters of sentimentalism, founds his position on the latter. Additionally, that all emotions are motivating appears to be taken as a truism by many within the psychology community. ${ }^{21}$ Prinz says:

In order to act, we must be motivated. Emotions and motivation are linked. Emotions exert motivating force. There is clinical evidence that, without emotions, people feel no inclination to act. (Prinz 2007, 17-18)

Prinz goes on to cite a Damasio and Van Hoesen (1983) article that discusses individuals with a condition called akinetic mutism. Damasio and Van Hoesen theorize that such individuals lie completely motionless because they have sustained damage to specific regions of the brain responsible for emotions. Without the ability to feel emotions, these individuals lack motivation to act in any fashion.

I do not deny that many emotions play a key role in motivation, but does akinetic mutism prove that all emotions motivate? It may be that without any emotional faculties a person will not have any inclination to act, but this, by itself, does not show that all emotions motivate. That is, it could be true that some subset of emotions is required to motivate action while it is also true that some other emotions don't play a direct motivational role. ${ }^{22}$ If it is possible that there are non-motivational emotions, it is also possible that those emotions constitute some moral judgments.

\footnotetext{
${ }^{20}$ Haidt identifies six moral foundations, and he associates those foundations with 'characteristic emotions' but he does not identify moral judgments with specific emotions, nor suggest that other emotions cannot play any role in the six moral foundations he identifies. See his (2012), especially chapters 6 and 7. See also Cameron et al. (2015).

${ }^{21}$ See for example Stangor and Walinga (2014, 441-442).

${ }^{22}$ Blasi (2001) criticizes the view that emotions are necessarily motivational. Additionally, in their ontology of emotion, Hasting et al. (2011) state that many emotions have action tendencies, but they do not include motivation to act in their definition of emotion.
} 
Prinz's chief inspiration, Hume, also thought that some emotions may not have a motivational function:

For pride and humility are pure emotions in the soul, unattended with any desire, and not immediately exciting us to action. But love and hatred are not compleated within themselves, nor rest in that emotion, which they produce, but carry the mind to something farther. (Hume 1896, 368)

So, it may be that without the ability to feel love and anger we wouldn't $d o$ anything at all, yet that still doesn't tell us that pride and humility necessarily motivate, and it is not abundantly clear that pride and humility are not moral emotions. If not all emotions motivate, this leaves open the possibility that there could be moral judgments that are composed of nonmotivating emotions.

Currently, it is simply not possible to prove that all emotions motivate, nor is it possible to concretely pinpoint some subset of emotions that make up all moral judgments, so the common idea expressed by Prinz that sentimentalism entails internalism could be false. No doubt we have felt our emotions motivate us to action; however, we can also think of emotional states that seem to play no role in motivating action; postulating some action for the latter emotions to supposedly motivate comes across as ad hoc. E.g., what actions do awe, satisfaction, astonishment, or pride motivate? What action does a feeling of the sublime motivate? What actions do moods motivate, such as general feelings of depression or anxiety? It is hard to see how all of these states could be necessarily actiondirecting.

In this section I have argued that internalism does not seem adequate for explaining the behavior of our students and their consideration of Singer's argument. Internalists could try to maintain either that a) the vast majority of our students are practically irrational; b) the vast majority of our students do not make real moral judgments; or c) the vast majority of our students are at least minimally motivated. ${ }^{23} \mathrm{I}$ argued that there is little reason to think that in this particular case (but not in other, similar situations) that our students do not make real moral judgments; I further argued that if our students are practically irrational, then basically all normal adults are practically irrational, and if that is the case, then the charge of irrationality seems to lose its normative force. Although (c) strikes me as the most

\footnotetext{
${ }^{23}$ They could also maintain some combination of these three is occurring in the classroom, which is slightly more plausible: some students are minimally motivated, some students are amoralists, and some students aren't making real moral judgments. As I discussed, however, we have independent reasons to be skeptical of each possibility.
} 
plausible response, it is problematic in that there is no way to show that individuals did in fact have some minimal motivation, and I offered reasons for rejecting the commonsense sentimentalist position that maintains that all emotions play a motivational role. At this point, it doesn't seem that the internalist theory, considered as a universal account of moral judgment, can offer a satisfying analysis of our students' behavior. Let us now turn to examining what the externalist has to say about the behavior and judgments of our students. To do so, we need to first examine what exactly the externalist believes.

\section{What the externalist has to say about our students' judgments and behaviors}

Externalists deny that there is an essential connection between making moral judgments and being motivated to act. Shafer-Landau $(2000,271)$ characterizes the position as little more than the rejection of internalism. The main idea is that a moral judgment is one thing, the motivation to act on that judgment is another; there is no necessary connection between a moral judgment and the desire to act. However, the externalist position is, in reality, more complicated than this. The rejection of internalism is typically conceptually connected to some other position that is simultaneously maintained, e.g., that moral judgments are always a kind of belief, and beliefs do not motivate; or that moral judgments are always the recognition of a moral fact, and the recognition of a fact does not motivate. For example, Brink $(1986,26)$ attacks the internalist thesis as part of a defense of moral realism and observes that many philosophers have maintained that moral realism and internalism are generally incompatible. In this respect, the externalist is just as committed to the idea that moral judgments form a distinct kind as the internalist is. What they disagree on is which significant features a judgment must have to be included in the class 'moral judgment'.

The chief argument in favor of externalism is merely an attempt to refute internalism, rendering externalism true by default. To refute internalism, the externalist typically appeals to a character known as the 'amoralist'. An amoralist is a hypothetical person described as someone who knows about moral values and makes moral judgments, but remains wholly unmotivated by them. ${ }^{24}$ Shafer-Landau makes clear how important the amoralist is for the defenders of externalism:

\footnotetext{
${ }^{24}$ The following authors discuss the amoralist: Bedke (2008), Brink (1986), Bromwich (2013), Buckwalter and Turri (2017), King (2018), Nichols (2002), Smith (1994), Sadler (2003), Shafer-
} 
[The externalist] need defend only the conceptual possibility of an agent who on a single occasion fails to be motivated by a moral judgment that he endorses.... Establishing the possibility is all we need to undermine [internalism]; one doesn't show [that] internalism [is] true just by showing (if one can) that there are in fact no amoralists. [Internalism] is vindicated if and only if there cannot be any such people. (Shafer-Landau 2000, 271)

Whether there could in fact be such a person as an amoralist is itself recognized as a contentious thesis in the literature (Shafer-Landau 2000; Mason 2008). The contentiousness regarding whether such a person could even exist makes clear that the amoralist trope is an intuition pump that essentially replicates the original controversy. For whether one thinks that there could be such a thing as an amoralist is contingent on one's intuitions about the nature of moral judgment. ${ }^{25}$ If one thinks that real moral judgments necessarily motivate (internalism), then one is likely to think that either there couldn't really be such a person as an amoralist, or that such a person, if they exist, isn't really making moral judgments, at least not in the same way that psychologically normal people do. ${ }^{26}$ If, on the other hand, one thinks that moral judgments are not necessarily motivating (externalism), then one likely thinks that amoralists are possible, and that they very well might exist, say, in the form of a moral cynic or psychopath. Whether amoralists really are possible isn't all that important here, in part because the figure of the amoralist does not seem to have advanced the debate on the nature of moral judgments in any significant way ${ }^{27}$ and in part because our classrooms are unlikely to be populated by vast tracts of amoralists. If our students did not have any feelings at all about the issue of world hunger, they certainly wouldn't squirm in their seats when the instructor points out the frivolous things they gladly use their spending money on without a second thought instead of contributing to famine relief. $^{28}$

\footnotetext{
Landau (2000), Sinnott-Armstrong (2014), and Svavarsdottir (1999). Further, the following authors consider the possibility that there are actual amoralists, namely, psychopaths: Kennett (2006), Matthews (2014), Maibom (2018), Nichols (2002), Smith (1994), and Sinnott-Armstrong (2014).

${ }^{25}$ And this difference in intuition may be traceable to the fact that different people hold slightly different, largely overlapping concepts of 'moral judgment'. See Francén (2010).

${ }^{26} \mathrm{~A}$ common internalist response to the amoralist example is to deny that amoralists are in fact making moral judgments in the same way as ordinary people, or even using moral language in the same way. See for example Hare (1952) and Smith (1994).

${ }^{27}$ See Francén (2010) and Rosati (2016) for a similar assessment.

${ }^{28}$ As discussed above, whether those feelings are motivational is a separate question. I don't doubt they felt something; I doubt all feelings motivate.
} 
Putting aside, for now, the hypothetical individual who can reach moral judgments and be wholly unmoved by them, how does the externalist explain ordinary moral decision-making and the reliable connection between moral judgment and behavior that we typically find? In explaining this reliable connection, Brink says the following:

Though it makes the motivational force of moral considerations a matter of contingent psychological fact, externalism can base this motivation on 'deep' or widely shared psychological facts.... [A]s a matter of contingent psychological fact, the vast majority of people will have at least a desire to comply (even) with other regarding moral demands. Moral motivation, on such a view, can be widespread and predictable, even if it is neither necessary, nor universal, nor overriding. (Brink 1986, 31)

Shafer-Landau also believes the connection between judgment and action will involve emotions and desires:

The importance of any such account [of moral motivation] is that it makes the existence of the relevant desires contingent. This is easily seen when it comes to socialization stories, which explain the desires that constitute conscientious motivation as arising from early moral education and upbringing. On this line, it is conceptually possible for moral judgments to fail to motivate because it is conceptually possible for individuals either to receive a quite poor early training, or to receive a fine one and later distance themselves from it in fundamental respects. (Shafer-Landau 2000, 287)

Someone new to philosophy, but a critical thinker nonetheless, might read these two passages and think: Wait, what's the difference between externalism and internalism? Aren't these two groups telling the same story as to why people act on their moral judgments? The answer to the second question is: Yes, they are telling the same basic story. Externalists believe that emotions and desires do in fact reliably motivate people to act on their judgments, just as internalists do. The difference is that externalists maintain that said reliable motivation is contingent. Both groups maintain that people reliably act on their moral judgments, and that in some cases it appears that individuals can make moral judgments without being motivated. Of course, for the internalist, this is merely an appearance that can be explained away. 
If all the externalist demands is that the philosophical community admit the conceptual possibility of an individual who makes a moral judgment and doesn't feel at all motivated by it, then I grant that conceptual possibility. But such a concession doesn't tell us anything at all about what is going on psychologically with any actual person when they make a moral judgment. What we should be interested in is whether such a person could exist, as that would actually tell us something about the ontology of moral judgment, and not merely the concept, which may fail to pick out any distinctive psychological process at all.

The externalist, then, finds herself in a similar position to the internalist when describing the behavior of our students. The externalist, as suggested by Brink and Shafer-Landau above, should be open to maintaining something quite similar to the internalist: because the students do likely feel some emotional response to Singer's article, and because externalists do in fact accept that emotions (contingently) motivate, when it comes to actual human beings (i.e., when excluding amoralists), moral judgments are at least minimally motivating. That is, they should be open to accepting something like weakest internalism as a fairly accurate descriptive account of human moral judgment. ${ }^{29}$

As Mason $(2008,144)$ points out, there is little meaningful difference between weakest internalism and externalism. Although Mason's point was that the internalist might as well adopt externalism, the argument seems to cut both ways. Once we grant the possibility that all moral judgments have some minimal motivational force, externalism seems to lose its appeal. For it seems that the externalist has to rule out an intuitive account of the failure to act by definition: the students are motivated by their judgments but not to a sufficient degree to give rise to action. ${ }^{30}$ For merely being weakly motivated is a more plausible explanation for failure to act on one's moral judgments than the explanations readily available to the externalist: e.g., maintaining that most students are themselves flawed in some way (i.e., they are amoralists), or that they had a flawed moral education, a possible explanation put forth by Shafer-Landau. For attributing failure of motivation to poor upbringing actually appears to cede some ground to the internalist: for she could then maintain that those

\footnotetext{
${ }^{29}$ On a position like community internalism (Drier 1990; Tresan 2006, 2009) it isn't even necessary that every individual within a given community feels motivated by their moral judgments, just so long as such judgments are made within the context of a community where individuals are reliably so motivated. On such a position, amoralists are in fact possible. On this view, moral motivation is contingently related to judgment at the individual level, just not at the community level. Here we might wonder how this view differs from the externalism as presented by Brink (1986), where he readily admits that most people will be reliably motivated by their judgments.

${ }^{30}$ Thanks to an anonymous reviewer for encouraging me to frame the problem for the externalist in this way.
} 
individuals who fail to be motivated at all never learned to make 'real' moral judgments, and 'real' moral judgments are always minimally motivating. Hence, the internalist thesis is saved.

\section{Shared assumptions of internalists and externalists}

The internalist/externalist debate appears to rest on a key assumption that is often left unstated: that moral judgments form a distinct kind, or category, of judgment; if they didn't form a distinct kind, it wouldn't make sense to wonder if all moral judgments had some set of shared, significant features. ${ }^{31}$ This assumption has the following entailment: if moral judgments form a distinct category or constitute a natural kind, then we should be able to identify some significant features that distinguish it from other kinds of judgments, such that if a judgment doesn't have said features it can't be a moral judgment.

Although several philosophers have in fact attempted to define what constitutes a moral judgment, a number of philosophers believe that a definition cannot be given. ${ }^{32}$ If philosophers consciously admit to themselves that it is difficult to specify whether a judgment constitutes a moral one beyond some core, indisputable cases, they likely shouldn't simultaneously maintain that the concept 'moral judgment' has some necessary, specifiable features. If we consider the possibility that moral judgments form a heterogeneous class, then we can begin to entertain the possibility that moral judgments made in some contexts always motivate, and when made in other contexts they fail to motivate, without also

\footnotetext{
${ }^{31}$ Michael Gill (2009) has also observed that most meta-ethical theorizing simply begins with the assumption that moral judgments form a uniform or distinct kind that admit of a single conceptual analysis; he further wonders whether we can determine ordinary speaker's meta-ethical commitments based on their usage of moral language. He also wonders if the concept 'moral judgment' is employed differently by different speakers, or differently by the same speaker in different contexts. In this paper, I am more concerned with the referent of 'moral judgment', i.e., does it actually pick out a distinct type or process of judging. Nonetheless, I believe Gill gives strong arguments against there being a uniform use of the concept.

${ }^{32}$ Shafer-Landau (2015), for example, does not believe 'morality' can be defined, which would seem to imply that 'moral judgment' is similarly undefinable. See his 'Introduction'. Smith (1994) takes it that there is a kind of commonsense understanding of 'moral judgment' such that it can be defined on the basis of moral platitudes. See his chapter 1; this idea will be subsequently challenged. Richardson (2018), in his Stanford Encyclopedia of Philosophy entry on moral reasoning states '[W]e will need to have a capacious understanding of what counts as a moral question. For instance, since a prominent position about moral reasoning is that the relevant considerations are not codifiable, we would beg a central question if we here defined "morality" as involving codifiable principles or rules'. Svavarsdottir admits that 'it is of course notoriously difficult to say what distinguishes moral judgments from other evaluative or normative judgments' $(1999$, n. 6). Drier states 'we should just admit that it may be vague whether a given judgment is moral or not' $(1996,411, n$. 419). I don't deny that there are widely accepted paradigm examples of moral judgments. Nonetheless, 'moral judgment' is clearly not a sharply defined concept, which philosophers seem to readily recognize.
} 
concluding that only one 'real' moral judgment was ultimately made. Do we have any strong reasons in favor of thinking that moral judgments do in fact form a distinct kind?

The chief evidence relied upon by contemporary meta-ethicists is generally drawn from observations about language use, and the position that moral judgments do form a distinct kind is rarely substantively, or directly, argued for. ${ }^{33}$ Gill aptly summarizes the recent state of the field:

Twentieth century meta-ethicists typically presented some examples of ordinary discourse. But they didn't gather data in any kind of comprehensive and systematic way.... For if the concept of morality is sharply unitary and robustly determinate - if the relevant meta-ethical information is encoded in the DNA of every use of moral terms - then one handful of commonsense judgments, intuitions, and platitudes will instantiate the same meta-ethical commitments as any other. (Gill 2009, 217, my italics)

However, as recent empirical work has shown, the assumptions of trained philosophers concerning the use of a concept have not always aligned with the thinking of non-philosopher language users. ${ }^{34}$ For example, metaethicists have typically inferred from language use that ordinary speakers are moral absolutists. ${ }^{35}$ Studies indicate this isn't true (Goodwin and Darley 2008; Beebe and Sackris 2016). Based on their research, Beebe and Sackris state 'Thus, we can see that because the strength of our participants' inclinations toward objectivism varies according to the issue in question, the question of whether they are moral objectivists is not going to have a simple "Yes" or "No" answer' $(2016,917)$. Perhaps we should then consider the possibility that the question as to whether moral judgments all motivate or all fail to motivate won't have a simple 'Yes' or 'No' answer either.

An analysis on which moral judgments do not form a distinct kind might explain, in part, why we have competing intuitions about the nature of moral judgment, and why certain kinds of cases trigger certain kinds of intuitions. We should notice that in the arguments for externalism, the key figure of the amoralist is rarely presented as failing to act on their considered moral judgment while directly confronted with the person who

\footnotetext{
${ }^{33}$ Kumar (2015) is the exception here.

${ }^{34}$ For example, studies seem to show that ordinary speakers do not always take justification as necessary for knowledge ascriptions. See Sackris and Beebe (2014).

${ }^{35}$ Smith, for example, states that "it is a platitude that our moral judgements at least purport to be objective" $(1994,84)$.
} 
will be injured/victimized by their failure to act. Instead, they are typically presented as being convinced by a moral argument concerning some faroff issue/individual and failing to act, much like the situation of our students in relation to the individuals of East Bengal.

Consider the following three examples:

Virginia has put her social position at risk to help a politically persecuted stranger because she thinks it is the right thing to do. Later she meets Patrick, who could, without any apparent risk to himself, similarly help a politically persecuted stranger, but who has made no attempt to do so. Our morally committed heroine confronts Patrick, appealing first to his compassion for the victims. Patrick rather wearily tells her that he has no inclination to concern himself with the plight of strangers... Patrick readily declares that he agrees with her moral assessment, but nevertheless cannot be bothered to help. (Svavarsdottir 1999, 176)

Imagine an introductory philosophy student who has become convinced of the truth of a crude sort of ethical relativism. She believes that the ultimate moral standard comprises the fundamental mores of the society in which an action is performed. Armed with this view of morality, she issues certain moral judgments that she takes to be correct. But she is alienated from her society. Or, more likely, though she finds much of the pre-vailing cultural code amenable, she rejects a strand. She is voicing what she takes to be the moral truth, yet is unmoved. (Schaffer 2000, 274)

Alice was raised to believe that the divine command theory is correct. That is, as Alice herself might say, she was raised to believe that our moral obligations are determined by the commands of God.... On the principle of an eye for an eye, Alice believes that capital punishment is obligatory in cases of murder, and she believes she has an obligation to support capital punishment. But she is deeply compassionate, and she is quite out of sympathy with what she takes to be God's vengefulness. Because of her compassion she is not motivated in the least to support capital punishment. She is in fact active in opposing it, even though she believes she is morally forbidden to do so. (Copp 1995, 190-191)

In my review of the literature, I have yet to find an argument in favor of externalism where an amoralist fails to act in response to some moral 
dilemma that directly confronts them. That is, there is no fictional example offered in support of externalism like this:

Bob is walking to campus to teach moral philosophy. Bob is completely proficient with moral terms and makes moral judgments all the time: of course, he understands morality - he holds the chair in moral philosophy! On the way to campus, Bob sees his neighbor's child drowning in a shallow pond. Bob could easily save the child by wading in and effortlessly plucking him out of the water. Bob knows that saving the child is the right thing to do, and judges it to be the right thing to do, yet he has no inclination to save the child. Besides, he doesn't want to be late for his own lecture on moral motivation. So, despite his judgment, Bob keeps walking.

Unsurprisingly, no one argues for externalism in this way. Perhaps this is because it is simply implausible to almost every party to the debate to imagine someone judging that it is right to save the drowning child right in front of them yet failing to be motivated by said judgment. What the Schaffer, Svavarsdottir, and Copp cases have in common is that the amoralist is not failing to help a desperate person right in front of them: they are merely failing to, in the case of the first example, help some abstract individual, and in the second and third cases they are failing to act on highly abstract moral judgments. In abstract, non-pressing cases of moral judgment, it may seem plausible that an individual could make such a judgment without being motivated. However, when confronted by a suffering person directly, it doesn't seem at all plausible that there could be an individual who makes a moral judgment yet fails to act. This result is suggestive. It suggests that moral judgments may not form a uniform and definitive class, at least when it comes to motivation: each side appeals to quite different examples, and the different examples yield differing intuitions, perhaps because our judgment processes are highly contextdependent.

\section{Conclusion}

The term 'moral judgment' has a lengthy philosophical history; nonetheless, I have argued here that we should entertain the possibility that this term does not pick out a naturally occurring category; that is, we should consider the possibility that the internalist/externalist debate is founded on the mistaken assumption that moral judgments constitute a distinctive kind. In fact, given the variety of objects and events that have been brought into the moral domain by human beings (especially in recent 
history), we should tend in just the opposite direction: if what constitutes the moral is so diverse, perhaps moral judgments themselves form a diverse group.

What, then, should we say about our students? Undoubtedly most make judgments and feel something when reading the Singer article, but likely different students feel different emotions and form different beliefs, and some of those emotions/beliefs may not be motivating, or so minimally motivating that the label "internalism" becomes meaningless. But if some set of judgments do in fact always motivate individuals to action (for whatever reason-perhaps because in some cases moral judgments are primarily composed of strong emotions), then the externalist label is meaningless as well; for, as discussed, the externalist thesis is typically tied to other claims about the essential nature of moral judgment.

As stated at the beginning of the article, I have little doubt that almost every student would spring into action to save the drowning child right in front of them. ${ }^{36}$ There are likely a great number of factors, including emotional ones, that would cause them to act in such a situation, but it may well be difficult to connect their motivation with any one particular factor. In that case, we should consider the possibility that moral judgment does not admit of a single, unified analysis, as well as the possibility that our concepts do not match up neatly with underlying psychological processes in a one-to-one fashion.

One final implication of the position argued for here to consider is that, if correct, we may no longer be able to draw a clear distinction drawn between 'bona fide' moral judgments and 'defective' ones; at the very least, moral judgments cannot be called defective on the grounds that they fail to motivate. ${ }^{37}$ As we have seen, internalists are fond of drawing such a distinction to defend their position: for example, Prinz argues that psychopaths are unable to form real moral judgments because they are unable to feel emotions in the same way as typical individuals; for Prinz (2007, 42-47), their inability to be motivated by their moral judgements supplies evidence that moral judgments, as formed my average individuals, are in fact rooted in emotions and thereby reliably motivating. ${ }^{38}$

\footnotetext{
${ }^{36}$ I am thinking almost all would at least dial 911.

${ }^{37}$ Thanks to an anonymous reviewer for encouraging me to consider this implication.

${ }^{38}$ The discussion of psychopaths in relation to the internalism/externalism debate is extensive. In addition to Prinz, the following authors consider the possibility that psychopaths constitute real-life counterexamples to internalism: Kennett (2006), Matthews (2014), Maibom (2018), Nichols (2002), Smith (1994), and Sinnott-Armstrong (2014).
} 
However, the inability of psychopaths to make moral judgments has been recently called into doubt. In a meta-analysis of research on psychopathic moral decision-making, Larsen et al. state that they 'found no empirical support for common perceptions of clinicians and laypeople that psychopaths are remorseless, unempathetic, and/or otherwise morally incapable' $(2020,10) .{ }^{39}$ In terms of the position argued for here, these findings are significant in this respect: If moral judgments do not form a uniform kind, determining whether someone has a sufficient grasp of the use of moral concepts should become rather difficult to discern, and that seems to be just what Larsen et al. have found. If what we refer to as 'moral judgments' have different features in different contexts, this also seems to suggest a way forward: to determine whether an individual has a defective conception of morality, we would have to expose them to a whole host of moral decision-making contexts, and they may well be proficient in some areas but not others. This suggests an avenue for further research in this area.

\section{Acknowledgements}

Thanks to Rasmus Rosenberg Larsen and Alex King for their helpful feedback on this manuscript.

\section{REFERENCES}

Aharoni, Eyal, Walter Sinnott-Armstrong, and Kent Kiehl. 2012. 'Can Psychopathic Offenders Discern Moral Wrongs? A New Look at the Moral/Conventional Distinction'. Journal of Abnormal Psychology 121 (2): 484-497. https://doi.org/10.1037/a0024796.

Beebe, James, and David Sackris. 2016. 'Moral Objectivism Across the Lifespan'. Philosophical Psychology 29 (6): 912-929. https://doi.org/10.1080/09515089.2016.1174843.

Bedke, Matthew. 2009. 'Moral Judgment Purposivism: Saving Internalism from Amoralism'. Philosophical Studies 144: 189-209.

https://doi.org/10.1007/s11098-008-9205-5.

Björnsson, Gunnar. 2002. 'How Emotivism Survives Immoralists, Irrationality, and Depression'. Southern Journal of Philosophy 40 (3): 327-344.

https://doi.org/10.1111/j.2041-6962.2002.tb01905.x.

\footnotetext{
${ }^{39}$ Others have reached a similar conclusion: see Aharoni et al. (2012), Borg and Sinnott-Armstrong (2013), and Marshall et al. (2018).
} 
Blackburn, Simon. 1984. Spreading the Word. Oxford: Oxford University Press.

Blasi, Augusto. 2001. 'Emotions and Moral Motivation'. Journal for the Theory of Social Behavior 29 (1): 1-19.

https://doi.org/10.1111/1468-5914.00088.

Brink, David. 1986. 'Externalist Moral Realism'. Southern Journal of Philosophy 24 (1): 23-41. https://doi.org/10.1111/j.2041-6962.1986.tb01594.x.

Bromwich, Danielle. 2013. 'Motivational Internalism and the Challenge of Amoralism'. European Journal of Philosophy 24 (2): 452-471. https://doi.org/10.1111/ejop.12053.

Buckwalter, Wesley and John Turri. 2017. 'In the Thick of Moral Motivation'. Review of the Philosophy and Psychology 8: 433453. https://doi.org/10.1007/s13164-016-0306-3.

Cameron, Daryl, Kristen Lindquist, and Kurt Gray. 2015. 'A Constructivist Review of Morality and Emotions: No Evidence for Specific Links between Moral Content and Discrete Emotions'. Personality and Social Psychology Review 19(4): 371-394. https://doi.org/10.1177/1088868314566683

Carroll, Noël. 2015. 'Defending the Content Approach to Aesthetic Experience'. Metaphilosophy 46 (2): 171-188.

https://doi.org/10.1111/meta.12131.

Copp, David. 1995. 'Moral obligation and Moral Motivation'. Canadian Journal of Philosophy 25: 187-219. https://doi.org/10.1080/00455091.1995.10717438.

Damasio, Antonio and Gary Van Hoesen. 1983. 'Emotional disturbances associated with focal lesions of the limbic frontal lobe'. In Neuropsychology of Human Emotion, edited by K.M. Heilman and P. Satz, 85-100. New York: Guilford Press.

Dreier, James. 1990. 'Internalism and Speaker Relativism'. Ethics 101 (1): 6-26.

Francén, Ragnor. 2010. 'Moral Motivation Pluralism'. Journal of Ethics 14: 117-148. https://doi.org/10.1007/s10892-010-9074-y.

Gill, Michael. 2009. 'Indeterminacy and Variability in Meta-Ethics'. Philosophical Studies 145 (2): 215-234. https://doi.org/10.1007/s11098-008-9220-6.

Haidt, Jonathan. 2012. The Righteous Mind: Why Good People are divided by Politics and Religion. New York: Pantheon Books.

Hare, Richard. 1952. The Language of Morals. Oxford: Clarendon Press. Harman, Gilbert. 1977. The Nature of Morality: An Introduction to Ethics. New York: Oxford University Press.

Hasting, Janna, Werner Ceusters, Barry Smith, and Kevin Mulligan. 2011. 'Dispositions and Processes in the Emotion Ontology'. ICBO: International Conference on Biomedical Ontology, 71-78. 
Hume, David. 1896. A Treatise of Human Nature. Edited by L.A. SelbyBigge. Oxford: Clarendon Press.

Goodwin, Geoffrey, and John Darley. 2008. 'The Psychology of MetaEthics: Exploring Objectivism'. Cognition 106: 1339-1366. https://doi.org/10.1016/j.cognition.2007.06.007.

Kennett, Jeanette. 2006. 'Do Psychopaths Really Threaten Moral Rationalism?' Philosophical Explorations 9 (1): 69-82.

https://doi.org/10.1080/13869790500492524.

King, Alex. 2018. 'The Amoralist and the Anaesthetic'. Pacific Philosophical Quarterly 99 (4): 632-663.

https://doi.org/10.1111/papq.12225.

Korsgaard, Christine. 1986. 'Skepticism about Practical Reason'. Journal of Philosophy 83 (1): 5-25. https://doi.org/10.2307/2026464.

Korsgaard, Christine. 1996. Creating the Kingdom of Ends. Cambridge: Cambridge University Press.

Kripke, Saul. 1980. Naming and Necessity. Cambridge: Harvard University Press.

Kristoff, Nicholas. 2015. 'The Trader Who Donates Half His Pay'. The New York Times. Accessed September 22, 2021.

https://www.nytimes.com/2015/04/05/opinion/sunday/nicholaskristof-the-trader-who-donates-half-his-pay.html

Kumar, Victor. 2015. 'Moral Judgment as a Natural Kind'. Philosophical Studies 172: 2887-2910. https://doi.org/10.1007/s11098-0150448-7.

Larsen, Ramus Rosenberg, Jarkko Jalava, and Stephanie Griffiths. 2020. 'Are Psychopathy Checklist (PCL) Psychopaths Dangerous, Untreatable, and Without Conscience? A Systematic Review of the Empirical Evidence'. Psychology, Public Policy, and Law 26 (3): 297-311. http://dx.doi.org/10.1037/law0000239.

Maibom, Heidi. 2018. 'What Can Philosophers Learn from Psychopathy?' European Journal of Analytic Philosophy 14 (1): 63-78. https://doi.org/10.31820/ejap.14.1.4.

Marshall, Julia, Ashley Watts, and Scott Lilienfield. 2018. 'Do Psychopathic Individuals Possess a Misaligned Moral Compass? A Meta-Analytic Examination of Psychopathy's Relations with Moral Judgment'. Personality Disorders: Theory, Research, and Treatment 9 (1): 40-50. https://doi.org/10.1037/per0000226.

Mason, Elinor. 2008. 'An Argument against Motivational Internalism'. Proceedings of the Aristotelian Society 108 (2): 135-156. https://doi.org/10.1111/j.1467-9264.2008.00240.x.

Matthews, Eric. 2014. 'Psychopathy and Moral Rationality'. In Being Amoral: Psychopathy and Moral Incapacity, edited by Thomas Schramme, 71-90. Cambridge: MIT Press. 
Nichols, Shaun. 2002. How Psychopaths Threaten Moral Rationalism: Is it Irrational to be Amoral? The Monist 85 (2) 285-303.

Nichols, Shaun. 2004. Sentimental Rules: On the Natural Foundations of Moral Judgment. Oxford: Oxford University Press.

Nichols, Shaun, and Michael Gill. 2008. 'Sentimentalist Pluralism: Moral Psychology and Philosophical Ethics'. Philosophical Issues 18 (1): 143-163.

https://doi.org/10.1111/j.1533-6077.2008.00142.x.

Prinz, Jesse. 2007. The Emotional Construction of Morals. New York: Oxford University Press.

Richardson, Henry. 2018. Moral Reasoning. The Stanford Encyclopedia of Philosophy, edited by Edward Zalta. Accessed September 22, 2021.

https://plato.stanford.edu/archives/fall2018/entries/reasoningmoral/.

Rosati, Connie. 2016. Moral Motivation. The Stanford Encyclopedia of Philosophy, edited by Edward Zalta. Accessed September 22, 2021. https://plato.stanford.edu/archives/win2016/entries/moralmotivation/.

Sackris, David and James Beebe. 2014. 'Is Justification Necessary for Knowledge?' In Advances in Experimental Philosophy, edited by James Beebe, 175-192. London: Bloomsbury.

Sackris, David and Rasmus Rosenberg Larsen. 2020. 'A Consideration of Carroll's Content Theory'. Journal of Value Inquiry 54: 245-255. https://doi.org/10.1007/s10790-019-09693-6.

Sadler, Brooke. 2003. 'The Possibility of Amoralism: A Defense against Internalism'. Philosophy 78 (1): 63-78.

https://doi.org/10.1017/S0031819103000044.

Setiya, Kieran. 2004. 'Against Internalism'. Noûs 38 (2): 266-298. https://doi.org/10.1111/j.1468-0068.2004.00470.x.

Shafer-Landau, Russ. 2000. 'A Defense of Motivational Externalism'. Philosophical Studies 97 (3): 267-291. https://doi.org/10.1023/A:1018609130376.

Shafer-Landau, Russ. 2015. The Fundamentals of Ethics. Oxford: Oxford University Press.

Sinnott-Armstrong, Walter. 2014. 'Do Psychopaths Refute Internalism?' In Being Amoral: Psychopathy and Moral Incapacity, edited by Thomas Schramme, 187-208. Cambridge: MIT Press.

Sinnott-Armstrong, Walter and Thalia Wheatley. 2012. 'The Disunity of Moral Judgment and why it Matters in Philosophy'. The Monist 95 (3): 355-377. https://doi.org/10.5840/monist201295319.

Sinnott-Armstrong, Walter and Thalia Wheatley. 2014. 'Are Moral Judgments Unified?' Philosophical Psychology 27 (4): 451-474. https://doi.org/10.1080/09515089.2012.736075. 
Singer, Peter. 1972. 'Famine, Affluence, and Morality. Philosophy and Public Affairs 1 (3): 229-243.

Slote, Michael. 2010. Moral Sentimentalism. Oxford: Oxford University Press.

Smith, Michael. 1994. The Moral Problem. Oxford: Blackwell Publishing.

Stangor, Charles, and Jennifer Walinga. 2014. Introduction to Psychology - 1st Canadian Edition. Victoria, B.C.: BCcampus. https://opentextbc.ca/introductiontopsychology/.

Stich, Steven. 2006. 'Is Morality an Elegant Machine or a Kludge?' Journal of Cognition and Culture 6 (1-2): 181-189. https://doi.org/10.1163/156853706776931349.

Stocker, Michael. 1979. 'Desiring the Bad: An Essay in Moral Psychology'. Journal of Philosophy 76 (1): 738-753. https://doi.org/10.2307/2025856.

Svavarsdottir, Sigrun. 1999. 'Moral Cognitivism and Motivation'. The Philosophical Review: 108 (2): 161-219. https://doi.org/10.2307/2998300.

Tresan, Jon. 2006. 'De Dicto Internalist Cognitivism'. Noûs 40 (1): 143165. https://doi.org/10.1111/j.0029-4624.2006.00604.x.

Tresan, Jon. 2009. 'The Challenge of Communal Internalism'. The Journal of Value Inquiry 43: 179-199. https://doi.org/10.1007/s10790008-9141-9. 
